\title{
Bacteriological Profile and Antimicrobial Susceptibility Pattern of Blood Culture Isolates among Septicemia Suspected Children in a Rural Tertiary Care Hospital
}

\author{
Sreedevi Hanumantha and Nazeema Tabaseera*
}

Kodagu Institute of Medical Sciences, Madikeri - 571201, Kodagu, Karnataka, India

\author{
*Corresponding author
}

\section{A B S T R A C T}

Blood stream infections are very common in paediatric age group and are one of the common causes of morbidity and mortality. Septicaemia gradually leads to serious consequences like shock, multi organ failure, DIC etc. Timely identification of causative pathogen by blood culture (gold standard) is important. Antibiogram also helps us to elevate consciousness on resistance problems and recognise prospect to decrease the use of inappropriate antibiotics. The study was undertaken to evaluate major bacterial isolates causing septicaemia and their antibiogram pattern. The present study was carried out on 252 clinically diagnosed septicaemia cases. The growth was identified by conventional biochemical tests. Antibiotic susceptibility test was done by modified Kirby - Bauer method. Drug resistant strains in primary screening were further processed for the detection of ESBL and MRSA strains. Bacteremia was more prevalent in $\leq 28$ days children which was stastistically significant. Majority of the female children showed significant bacteremia compare to male children. $K$ pneumonia was more prevalent, C. fruendii and S. typhi were the least prevalent bacteria. 50\% of $S$ aureus were MRSA which is matter of concern. Sepsis is a medical emergency which requires timely detection and identification of blood borne pathogens with urgent rational antibiotic therapy. Infants and children are the vulnerable population to contract illness because of their weak immune barrier. Antibiotic sensitivity pattern to common pathogens has been changing from day to day and it is important to have latest information for guiding local empirical

\section{Introduction}

Blood stream infections are very common in paediatric age group and are one of the common causes of morbidity and mortality. ${ }^{2,5}$ Children with septicaemia present with fever, difficulty in breathing, tachycardia, malaise, refusal of feeds/lethargy which may gradually lead to serious consequences like shock, multi organ failure, DIC etc requiring rapid and aggressive antimicrobial treatment. ${ }^{5}$ Hence, blood stream infections constitute one of the most serious situations and timely identification of causative pathogen by blood culture (gold standard) is important.

The success of recovery of microorganisms from blood depends upon specimen collection, methods, blood volume, number and timing of blood cultures, interpretation of results and type of patient population being served by laboratory. Adequate rational data 
on bacterial pathogens causing neonatal sepsis along with their antibiogram aids the clinicians in the exponential treatment of infections prior to availability of antimicrobial susceptibility results. Antibiogram also helps us to elevate consciousness on resistance problems and recognise prospect to decrease the use of inappropriate antibiotics. Hence, the study was undertaken to evaluate major bacterial isolates causing septicaemia and their antibiogram pattern.

\section{Materials and Methods}

The present study was carried out between April 2012 and March 2013 in Department of Microbiology, Adichunchanagiri Institute of Medical Sciences, B.G.Nagara.

Under aseptic precautions, blood for culture and AST was collected from 252 clinically diagnosed septicaemia cases (Table 1). $1 \mathrm{ml}$ from neonates and $5 \mathrm{ml}$ from children was collected and inoculated into 10 and $50 \mathrm{ml}$ respectively into BHI broth (1:10 dilution). The culture bottles were incubated at $37^{\circ} \mathrm{C}$ aerobically and periodic subcultures were done onto Mac conkey's agar, Blood agar and Chocolate agar after overnight incubation on 3,5 , and on day 7 . The obtained growth was identified by conventional biochemical tests.

Antibiotic Susceptibility Test: The standard disc diffusion test for susceptibility to routine antibiotics was done by modified Kirby Bauer method. Zone sizes were measured and interpreted according to CLSI standards. Drug resistant strains in primary screening were further processed for the detection of ESBL strains and MRSA strains.

\section{Results and Discussion}

Chi-square test and ANOVA is applied for statistical analysis to show the association between bacteraemia.
Of the total 252 clinically diagnosed septicaemia cases culture positivity was seen in $26.9 \%$ which was in concordance with studies by Tiwari, Mehrotra, Negussie with $25 \%, 23.1 \%, 27.9 \%$ respectively. ${ }^{2,3,5}$ While others have reported higher rates of $43.78 \%$, $44.4 \%$ and $72.7 \% .^{1,2,6}$

In our study, bacteraemia was significant in females with $30.3 \%$ than males $23.07 \%$ which was statistically significant $(\mathrm{p}<0.01)$. Whereas studies by Mehrotra et al., Pooja et al., Sarangi et al., have reported higher rates in males. $^{3,4,6}$

According to age, bacteraemia was more prevalent in $\leq 28$ days with $26.5 \%$ which was statistically significant $(\mathrm{p}<0.05)$, and was in concordance with Sarangi et al., with $46.3 \%{ }^{6}$ The isolation of gram negative organisms was $69.1 \%$ and that of gram positives was $30.8 \%$, similar results have been given by studies of Tiwari et al., Mehrotra et al., Pooja et al., Negussie et al., ${ }^{2,3,4,5}$,While studies by Sarangi ${ }^{6}$ have reported higher incidence of gram positives $(75 \%)$ than the gram negatives (59\%). K. pneumoniae (32.3\%) was more prevalent and C. freundii $(4.4 \%)$ and $S$. typhi $(4.4 \%)$ were the least prevalent in present study.

This was in concordance with the studies by Tiwari et al., Mehrotra and Mishra. ${ }^{2,3}$ While studies by Pooja et al., Negussie et al., Enrera et al., Bhaumik ${ }^{4,5,7,8}$ have reported higher incidences of $B$ cepacia, Serratia species, Enterobacter species and Pseudomonas species respectively. $50 \%$ of $S$. aureus were MRSA which is a matter of concern in present study (Table 2).

A similar high incidence of MRSA was reported by Pooja et al., $(52 \%)^{4}$, Negussie et al., (38.5\%) 5, Kumar et al., (17.2\%) ${ }^{9}$, Mehrotra and Mishra ${ }^{2}$ and Tiwari et al., ${ }^{3}$ with $33.33 \%$ respectively. 
Table.1 Association between bacteraemia and demographic profile of study group

\begin{tabular}{|l|l|lc|}
\hline Age Group & No of children & Positive cultures (no) & (\%) \\
\hline $1 . \quad \leq 28$ days & 162 & 43 & $26.5 \%$ \\
$2 . \quad>28$ days -2 years & 48 & 07 & $14.5 \%$ \\
$3 . \quad>2-12$ years & 42 & 18 & $42.8 \%$ \\
\hline Gender & & & $23.07 \%$ \\
\hline $1 . \quad$ Male & 117 & 27 & $30.3 \%$ \\
\hline 2. Female & 135 & 41 & \\
\hline Total & 252 & 68 & \\
\hline
\end{tabular}

Table.2 Distribution of pathogenic isolates obtained from blood cultures

\begin{tabular}{|l|lc|}
\hline Bacterial Isolates & Number & $(\mathbf{\%})$ \\
\hline Escherichia coli & 13 & $19.1 \%$ \\
\hline Klebsiella pneumonia & 22 & $32.3 \%$ \\
\hline Citrobacter freundii & 03 & $4.4 \%$ \\
\hline Pseudomonas aeruginosa & 06 & $8.8 \%$ \\
\hline Salmonella typhi & 03 & $4.4 \%$ \\
\hline Staphylococci & 12 & $17.6 \%$ \\
\hline CONS & 09 & $13.2 \%$ \\
\hline Total & 68 & \\
\hline
\end{tabular}

Table.3 Antibacterial resistance pattern of the Gram positive blood stream isolates

\begin{tabular}{|l|lc|lc|}
\hline Antibiotics & \multicolumn{2}{|l|}{\begin{tabular}{l}
\multicolumn{2}{|l|}{ Staphylococcus } \\
aureus(n=12)
\end{tabular}} & \multicolumn{2}{l|}{ CONS (n=09) } \\
& No & $\%$ & \multicolumn{2}{l|}{ No } \\
\hline Penicillin & 06 & $50 \%$ & 03 & $33.3 \%$ \\
\hline Amoxyclav & 04 & $33.3 \%$ & 02 & $22.2 \%$ \\
\hline Amikacin & 01 & $8.3 \%$ & 0 & 0 \\
\hline Cefoxitin & 06 & $50 \%$ & 02 & $22.2 \%$ \\
\hline Ciprofloxacin & 03 & $25 \%$ & 02 & $22.2 \%$ \\
\hline Vancomycin & 0 & 0 & 02 & $22.2 \%$ \\
\hline Gentamycin & 03 & $25 \%$ & 01 & $11.1 \%$ \\
\hline Cefotaxime & 03 & $25 \%$ & 01 & $11.1 \%$ \\
\hline Co-trimaxazole & 03 & $25 \%$ & NT & \\
\hline
\end{tabular}


Table.4 Antibacterial resistance pattern of the Gram negative blood stream isolates

\begin{tabular}{|c|c|c|c|c|c|c|c|c|c|c|}
\hline \multirow{2}{*}{ Antibiotics } & \multicolumn{2}{|c|}{$\begin{array}{l}\text { Escherichia } \\
\text { coli }\end{array}$} & \multicolumn{2}{|c|}{$\begin{array}{l}\text { Klebsiella } \\
\text { pneumonia }\end{array}$} & \multicolumn{2}{|c|}{$\begin{array}{l}\text { Citrobacter } \\
\text { freundii }\end{array}$} & \multicolumn{2}{|c|}{$\begin{array}{l}\text { Pseudomonas } \\
\text { aeruginosa }\end{array}$} & \multicolumn{2}{|c|}{ S. typhi } \\
\hline & $\begin{array}{l}(\mathrm{n}= \\
\text { No }\end{array}$ & $\%$ & $\begin{array}{l}(\mathrm{n}= \\
\text { No }\end{array}$ & $\%$ & $\begin{array}{l}(\mathrm{n}= \\
\text { No }\end{array}$ & $\%$ & $\begin{array}{l}(\mathrm{n}= \\
\text { No }\end{array}$ & $\%$ & $\begin{array}{l}(\mathrm{n}= \\
\text { No }\end{array}$ & $\%$ \\
\hline Ampicillin & 08 & 61.5 & 06 & 27.2 & 01 & 33.3 & 0 & & 01 & 33.3 \\
\hline Amoxyclav & 05 & 38.4 & 09 & 40.9 & 0 & & 0 & & 01 & 33.3 \\
\hline Amikacin & 0 & & 07 & 31.8 & 01 & 33.3 & 0 & & 0 & \\
\hline Cotrimaxazole & 07 & 53.8 & 07 & 31.8 & 0 & & 0 & & 01 & 33.3 \\
\hline Gentamycin & 02 & 15.3 & 03 & 13.6 & 0 & & 0 & & 0 & \\
\hline Ciprofloxacin & 04 & 30.7 & 07 & 31.8 & 01 & 33.3 & 0 & & 02 & 66.6 \\
\hline Cefotaxime & 08 & 61.5 & 07 & 31.8 & 01 & 33.3 & 03 & 50 & 0 & \\
\hline Ceftazidime & 06 & 46.1 & 06 & 27.2 & 0 & & 04 & 66.6 & 01 & 33.3 \\
\hline Imipenem & 0 & & 0 & & 0 & & 0 & & 0 & \\
\hline Piperacillin+Tazobactum & 0 & & 02 & 9.1 & 0 & & 2 & 33.3 & 0 & \\
\hline Ceftriaxone & 04 & 30.7 & 0 & & 0 & & 0 & & 0 & \\
\hline
\end{tabular}

High resistance to Ampicillin was noted by most of Enterobacteriaciae. Klebsiella species showed highest resistance to almost all the drugs tested (Table 3) except Imipenem and Ceftriaxone. Among the other members of family Enterobacteriaciae except S.typhi and $C$. freundii, high resistance was seen to third generation Cephalosporins (Table 4).

Sepsis is a medical emergency which requires timely detection and identification of blood borne pathogens with urgent rational antibiotic therapy. Infants and children are the vulnerable population to contract illness because of their weak immune barrier. Antibiotic sensitivity pattern to common pathogens has been changing from day to day and it is important to have latest information for guiding local empirical choice of antibiotics.

\section{References}

Bhaumik. P. V, Purav. G. P, Payal. R. N, Mitesh.P. H, Piyusa P. H, Mahendra V.M. Bacteriological profile and antibiogram of gram negative organisms isolated from medical and neurology intensive care unit with special reference to multi- drug resistant organisms. Nat J Med Res 2012; 2(3):335-8.

Enrera J.A, Alcantara T Y, Shammari A A, Rashidi A E F A, Edelee H A A and Rashidi S M A. Antibiogram of bacterial isolates at Hail general hospital, KSA June 1- December 31, 2012. IOSR-JNHS 2015; 4(1):21-6.

Kumar. S, Joseph. N, Eason. J, Singh.R, Umadevi. $\mathrm{S}$ and Pramodini.S et al., Prevalence and current antibiogram of Staphylococci isolated from various clinical specimens in a tertiary care hospital in Pondicherry. Internet $\mathbf{J}$ Microbiol 2012; 10(1):1-6.

Mehrotra. A, Mishra. S. Determination of the causative agents of bacteremia in children under 5 years and their susceptibility pattern to the antibiotics. Global J Med Res 2014; 14(1):19-23.

Negussie A, Mulageta. G, Bedru A, Ali I, Shimeles D, Lema $\mathrm{T}$ et al., Bacteriological profile and antimicrobial susceptibility pattern of blood culture isolates among septicemia 
suspected children in selected hospitals Addis Ababa, Ethiopia. Int J Biol Med Res. 2015;6(1):4709-17.

Parashar. S. coagulase negative Staphylococcus : a cause of nosocomial blood stream infection. IJSR 2014; 3(6):277-78.

Pooja. R, Sowmya. K. N, Shrikala. B, Radhakrishna. M and Keerthiraj Bele. A spectrum of Bacterial Pathogens and its Antibiotic Susceptibility pattern Isolated from Neonatal Sepsis in an NICU in a Government Paediatric Hospital. Int. Res. J. Biologial Sci 2015; 4(5):50-4.

Prabhu. K., Bhat. S, Rao. S. Bacteriologic Profile and Antibiogram of Blood
Culture Isolates in a Pediatric Care Unit. JLP 2010; 2(2):85-7.

Sarangi K.K, Pattnaik. D, Misura S. N, Nayak M.K, Jena. J. Bacteriological profile and antibiogram of blood culture isolates done by automated culture and sensitivity method in a neonatal intensive care unit in a tertiary care hospital in Odisha, India. Int J Adv Med 2015; 2(4): 387-92.

Tiwari DK, Golia S, K.T Sangeetha, C. L Vasudha. A study on the bacteriological profile and antibiogram of bacteremia in children below 10 years in a tertiary care hospital in Bangalore, India. JCDR 2013; 7(12):2732-35.

\section{How to cite this article:}

Sreedevi Hanumantha and Nazeema Tabaseera. 2017. Bacteriological Profile and Antimicrobial Susceptibility Pattern of Blood Culture Isolates among Septicemia Suspected Children in a Rural Tertiary Care Hospital. Int.J.Curr.Microbiol.App.Sci. 6(11): 1167-1171. doi: https://doi.org/10.20546/ijcmas.2017.611.139 